\title{
YOUTH CONCEPTUALIZATION OF RESILIENCE STRATEGIES IN FOUR LOW- AND MIDDLE-INCOME COUNTRIES
}

\author{
Panos Vostanis, Sadiyya Haffejee, Hikmet Yazici, Sajida Hussein, \\ Munevver Ozdemir, Cansu Tosun, and John Maltby
}

\begin{abstract}
The concept of resilience is increasingly influential in the development of interventions and services for young people, yet there is limited knowledge of how resilience-building strategies are conceptualized by young people across different cultures, particularly in low- and middle-income countries. The aim of this study was to capture 274 young people's voices in disadvantaged communities in Kenya, Turkey, Pakistan, and Brazil through participatory research methods. Young people defined strategies in response to 4 adversity scenarios reflecting socioecological systems (young person, family, school, and community). Template analysis, underpinned by thematic design, was used to establish three broad themes of intrapersonal (self-management, cognitive re-appraisal, agency), interpersonal (social engagement, informal supports, formal supports), and religious resources. Proposed strategies were largely similar across the sites, with some contextual differences depending on the scenario (stressor) and cultural group. The findings support an ecological systems approach to resilience, which is consistent with the development of multimodal interventions for vulnerable youth and their families in disadvantaged communities in low- and middle-income countries.
\end{abstract}

Keywords: young people, resilience, participatory research, psychosocial, crosscultural, low- and middle-income countries

Panos Vostanis MD (corresponding author) is a Professor of Child Mental Health at the University of Leicester; George Davies Centre, University Road, Leicester LE1 7RH, UK. Email: pv11@le.ac.uk

Sadiyya Haffejee PhD is a Research Fellow at the University of KwaZulu-Natal, 238 Mazisi Kunene Rd, Glenwood, Durban, 4041, South Africa. Email: sadiyya.haffejee@ gmail.com

Hikmet Yazici PhD is a Professor of Psychological Counselling and Guidance at Trabzon University, 61335, Trabzon, Turkey. Email: hyaziciktu@gmail.com

Sajida Hussein PhD is a Director in the Child Development Programme, Hussaini Foundation, Karachi, Pakistan. Email: sajida79@googlemail.com

Munevver Ozdemir MA is a Research Assistant at Trabzon University, 61335, Trabzon, Turkey. Email: mnvr.ozdemir@outlook.com

Cansu Tosun BA is a Research Assistant at Trabzon University, 61335, Trabzon, Turkey. Email: cansu.tosun@ktu.edu.tr

John Maltby PhD is a Professor of Differential Psychology at the University of Leicester, George Davies Centre, University Road, Leicester LE1 7RH, UK. Email: jm148@1e.ac.uk 
Globally, there is growing recognition of the need to increase the priority of addressing the mental health needs of young people (Patel \& Rahman, 2015). Young people are potentially at risk for a range of adverse psychosocial outcomes resulting from exposure to complex vulnerability factors - such as adverse living conditions, poverty, violence, migration, and exposure to environmental hazards and communicable diseases - coupled with limited access to appropriate services and supports (Getanda et al., 2017; Kieling et al., 2011). Recent years have thus seen an expansion of research focused on factors that enable and support children's resilience in the face of personal, familial, and environmental hazards (Ungar, 2004).

In spite of considerable academic disparity in defining and explaining resilience processes, there is increasing consensus that resilience is not an inherent, static trait that resides within an individual (Garmezy, 1991; Masten, 2006; Rutter, 2006; Theron, 2018; Ungar, 2011; Werner, 1989). Researchers in this field concur that resilience is a complex phenomenon that is sensitive to and dependent on sociocultural and contextual factors (Maltby et al., 2016; Panter-Brick, 2015; Theron, 2018; Ungar, 2011). In this way, resilience researchers acknowledge, to varying degrees, the role of the environment in nurturing resilience. Ungar $(2011,2012,2015)$ urged a shift in our understanding of resilience by highlighting the seminal importance of both context and culture in his socioecological theory of resilience (SERT). Ungar $(2011,2012)$ thus held that resilience is a dynamic, culturally entrenched process shared between an individual and their context; in SERT, he introduced principles of decentrality and cultural relativity. Decentrality advocates for a shift in focus, away from the children themselves and towards what is happening around them that facilitates resilience, while cultural relativity suggests that adaptation is embedded in culture.

Masten and Wright (2010) identify six universally occurring adaptive systems that inform resilience: the presence of supportive attachment relationships; the individual's cognitive aptitude; self-regulation skills; the ability to make meaning; agency and mastery; and the influence of culture and traditions. The way these systems operate, however, varies across contexts and periods, and their use in analysis thus needs to be grounded in contextual awareness (Theron, 2018; Theron \& Theron, 2013; Ungar, 2015). This focus on cross-cultural understanding of resilience is becoming increasingly popular, as it enables a more nuanced understanding of adaptive processes across cultures and nations (Sirikantraporn et al., 2018).

The development of culturally sensitive and contextualized interventions requires a clearer understanding of how resilience and resilience-building are characterized by young people, families, and communities, especially in life circumstances of conflict and disadvantage (Tamburrino et al., 2018). Youth in these contexts experience different adversities and have access to different resources. Like adversity, resilience is thus conceptualized differently depending on context and culture (Huang, 2018). What may be seen as resilience in one context might not be seen that way in another. Context and culture determine the meaning apportioned to manifestations of resilience (Panter-Brick, 2015). For example, studies conducted with youth in sub-Saharan 
countries highlight the importance of social and kin relationships and of education in the resilience processes of youth (Theron \& Phasha, 2015; Theron \& van Rensburg, 2018; van Breda \& Theron, 2018). For young people in Pakistan, sharing problems with families was ranked highly, in contrast to the value placed upon independent decision-making in Western cultures (Sahar \& Muzaffar, 2017). For child labourers in Brazil, Libório and Ungar (2014) found that protective processes related to resilience were partly present as a result of the "pattern of protagonism among these youth" (p. 682). Four types of protective processes were identified: improving behaviour and view of oneself, increasing positive engagement with others, actively participating in the community, and engaging in cultural activities including the practice of artistic skills. Based on these findings, Libório and Ungar (2014) concluded that resilience processes for youth in Brazil are products of the individual's subjectivity, their active engagement in interpersonal relationships, and their participation in valued cultural practices; hence resilience processes work in harmony with a facilitative social ecology.

Despite the increasing interest in young people's resilience across the world, and how this could be informed by the socioecological systems model, there is limited knowledge on how different resilience strategies could be devised by youth across cultural contexts and socioecological levels. There is also sparse evidence on how different types of resilience strategies may be linked to help-seeking patterns and to existing supports and services, particularly in lowand middle-income countries (LMIC) and areas of disadvantage. In recent years, we have developed a global program of mental health service transformation for vulnerable young people in LMIC, called World Awareness for Children in Trauma ${ }^{1}$ (WACIT; Vostanis, 2018, 2019). This program is based on an interdisciplinary scaled service model (United Nations High Commissioner for Refugees, 2013; World Health Organization, 2008) to address young people's mental health needs at different socioecological levels by intervening through the young person and their family, school, and community. To date, we have captured the perspectives of adult stakeholders who have identified key barriers to access to mental health care. These included the stigma of mental illness, lack of awareness, lack of parental engagement, and absence of interdisciplinary cooperation (Vostanis, Maltby, et al., 2018). So far, young people's voices have been absent in informing culturally appropriate and engaging interventions and services in LMIC. This study, therefore, attempts to fill this gap by exploring how young people across four culturally and contextually different communities in Kenya, Turkey, Brazil, and Pakistan conceptualized resilience strategies.

${ }^{1}$ www.wacit.org 
International Journal of Child, Youth and Family Studies (2020) 11(1): 92-111

\section{Method}

The study aimed to address the following research questions:

1. How do young people formulate resilience strategies when faced with different adversity scenarios reflecting the levels of the socioecological model?

\section{How do these strategies contrast across cultural groups in four LMIC?}

Consistent with these research questions, while placing the method in a person-centred and culturally appropriate context, a participatory research design was adopted. This research tool enables groups collectively affected by a problem to "participate" in the process of developing "actions" to address that problem. Consequently, this approach enables the active engagement of community members to raise awareness of the issues, and relies on them as a source of expertise in facilitating possible solutions (Reason, 1994). The process of engagement and co-production recognizes the relevance and importance of language and shared meaning, as well as emphasizing and valuing participants' voices. Consistent with this, therefore, a social constructionist personcentred theoretical framework underpinned our methods. This approach to data collection and the analytic process identifies and illuminates the constructed accounts of the young participants (Burr, 2003).

Participatory research is increasingly used to cooperatively address problems affecting individuals who are marginalized or excluded from service planning and implementation, such as youth from disadvantaged LMIC communities (Rhodes et al., 2015; Willow, 2013). Participants do not focus on merely understanding a given problem; rather, participants and researchers develop actions collectively (Kidd \& Kral, 2005).

\section{Context and Participants}

Young people were selected from four LMIC across the socioeconomic spectrum (Organization for Economic Cooperation and Development, 2016). The sites were partners to the previously described WACIT program. Within each country, a host non-governmental organization (NGO) acted as facilitator and gatekeeper to the study. The target population included young people in disadvantaged urban communities in Nakuru, Kenya; Rio de Janeiro, Brazil; Trabzon, Turkey; and Karachi, Pakistan. In Pakistan, young people in care were also included as an additional representation of young people with complex psychosocial needs. This research focused on young people's voices, as it is important to understand how they define resilience strategies and help-seeking, in order to develop engaging, youth-friendly interventions and services. Young people were recruited from schools in collaboration with a host NGO, which also acted as the partner of the wider WACIT program in each country (Vostanis, O'Reilly, et al., 2018). Although we aimed to include age groups of mid-to-late adolescence in each country, this was not possible in Brazil, where the collaborating school was a primary education setting, so we 
included their oldest grade. In total, 274 young people between the ages of 10 and 17 years took part. Their characteristics are described in Table 1.

Table 1. Characteristics of Participating Young People (N=274)

\begin{tabular}{llccccc}
\hline Country & Location & $n$ & Groups & Gender F & Gender M & Age \\
\hline Kenya & School 1 & 19 & 3 & 9 & 10 & 14 \\
Kenya & School 2 & 48 & 6 & 19 & 29 & $15-17$ \\
Turkey & School 1 & 32 & 5 & 16 & 16 & 16 \\
Turkey & School 2 & 35 & 5 & 18 & 17 & 16 \\
Brazil & School 1 & 17 & 4 & 8 & 9 & $10-11$ \\
Pakistan & School 1 & 23 & 6 & 18 & 5 & 13 \\
Pakistan & School 2 & 34 & 4 & 19 & 15 & $13-14$ \\
Pakistan & Care Home & 66 & 6 & 66 & 0 & $10-13$ \\
\hline
\end{tabular}

\section{Research Procedure}

Young people were asked to define resilience strategies in response to scenarios that were considered common and easily understood within their sociocultural context. The scenarios were underpinned by the ecological systems framework; that is, they were developed to reflect stressors at four levels representing distinct socioecological locations: within the young person, their family, their school, and their community (Bronfenbrenner, 1979). Scenarios were created based on the literature, then revised in consultation with the host facilitators. It was concluded that three scenarios relating resepctively to the young person, the family, and the school were universal to all countries, while the fourth, concerning the community, varied even within each country. For this reason, the community scenario was customized by each of the four host facilitators. Young people were asked how they could feel better, or advise another young person in the same situation to feel better, if faced with the following scenarios, each at a different socioecological level:

- Young person: Feeling sad or unhappy, without being aware of a specific trigger.

- Family: Parents, caregivers, or other adults arguing verbally or physically at home.

- School: Another young person calling them names or hurting them at school (all groups understood the word "bullied").

- Community: Scenarios were codeveloped, depending on the context and common events in each country and community:

- Kenya: No water in the neighbourhood or community.

- Turkey: Fire in the neighbourhood or community.

- Brazil: Violence in the neighbourhood or community.

- Pakistan schools: Criminality in the neighbourhood or community.

- Pakistan care home: Frequent power breakdowns (lasting more than 8 hours). 
Ethics approval was granted by the University of Leicester Psychology Research Ethics Committee following the ethical principles of the Declaration of Helsinki, with the host agencies acting as gatekeepers. Parents (or legal guardians for young people in care) and young people provided consent to take part. Within each workshop, young people were asked to break into small mixed-gender groups of 6-8 participants each. They were given pens and a large piece of paper for each exercise. Young people were free to interact and discuss their responses, but were encouraged to write them down ("there is no right or wrong"). They were encouraged to support their written statements with drawings if they found it useful to do so. This option was mainly used by the youngest group, in Brazil.

Each small group had a young facilitator in the discussion, who was also responsible for collating co-produced responses in writing. In Kenya, the discussions were largely in English, and partly in Swahili; all collected material was in English. In Turkey and Brazil respectively, discussions and collected material were in Turkish and Portuguese; these were subsequently translated into English. In Pakistan, the school participants carried out their discussions in English and Urdu, and wrote in English; while in the care home, the young people spoke and wrote in Balti (Figure 1), and their materials were translated into English.

Figure 1. Example of Materials Created in Response to Scenario 1 (Feeling Sad) in Pakistan

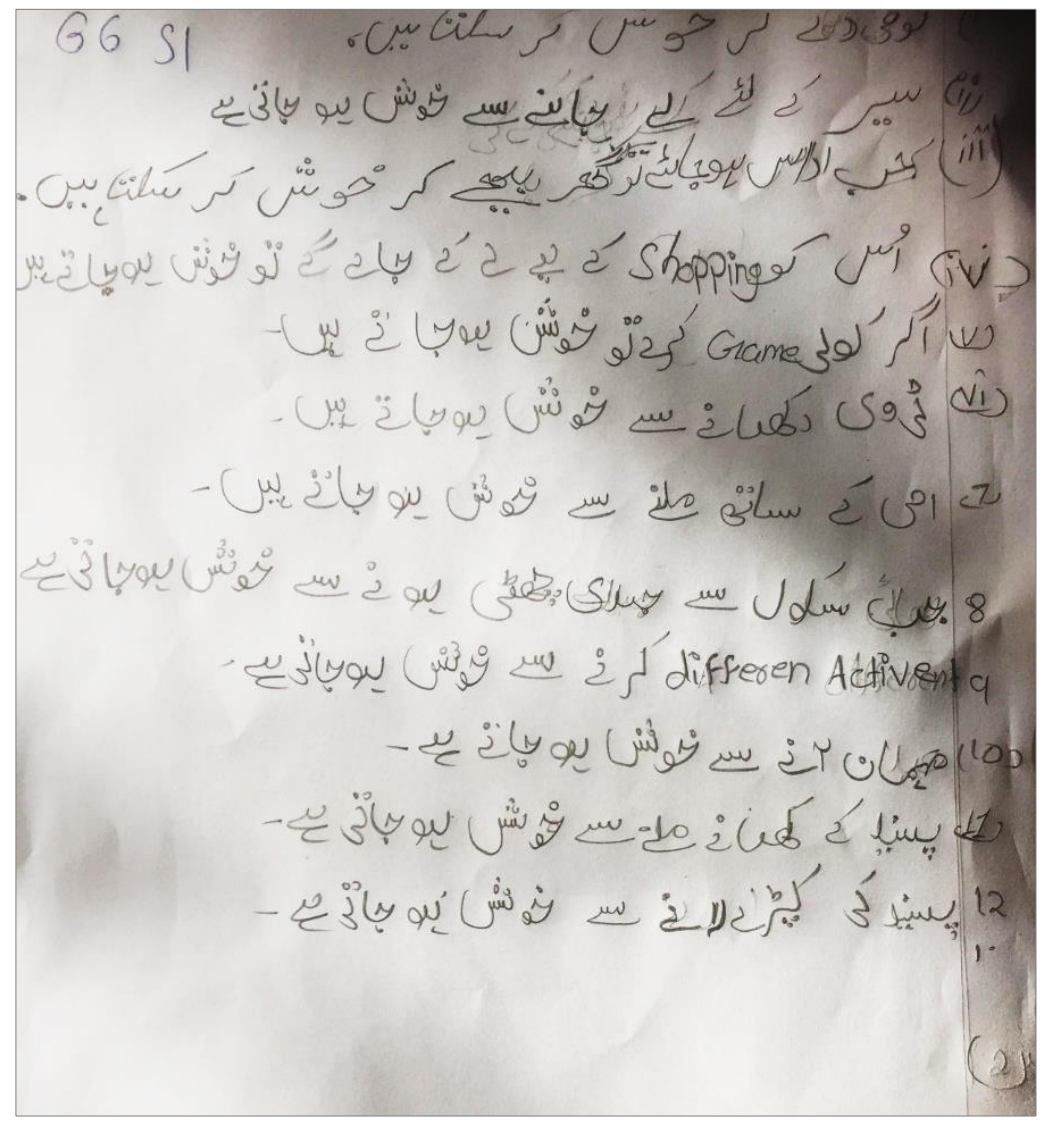




\section{Analytic Approach}

Because of the required participatory methods, the age and cultural diversity of the participants, and the complexity of the evidence surrounding resilience in LMIC, it was deemed appropriate to utilize template analysis to address the research questions. Template analysis is a form of thematic analysis (Braun \& Clarke, 2006) that identifies salient issues in the data and the literature to represent the key topics at stake (King, 2004). Its emphasis is on participant meaning creation; to this end, it provides a structural framework to create a template of categories. The initial template was shaped and informed by the adopted conceptual framework (ecological systems and the four related scenarios). However, the template was bidirectional, in the sense that it was further influenced by the social-constructionist theoretical framework and by the youth perspectives that emerged through the participatory techniques. The template analysis thus allowed the research agenda and evidence base to influence the initial template design.

This further encouraged the refinement and redevelopment of the template through the iterative inclusion of participant views to map and distinguish between relevant concepts (Johnson et al., 2013). The template was codeveloped within the team, as first-order categories were identified by authors Tosun and Vostanis. These were then subjected to second-order analysis by authors Haffejee and Vostanis to establish the final themes and subthemes across domains and countries, thus arriving at the final template. The analysis was data-driven: the emerging themes and subthemes were not mapped onto existing resilience theories during the analytic stage, although the findings are critically considered in the context of key theories and classifications in the Discussion section of this article.

\section{Results}

Template analysis was thus utilized to identify common resilience-building strategies (categories) across the four scenarios, as put forward by the 274 young people from the four LMIC. Emerging categories at the first analytic stage were combined into three themes and six subthemes in the second-order analysis, as presented in Table 2. Themes had different numbers of subthemes and categories. For example, religion was considered a conceptually independent theme, despite the smaller amount of data and lack of subthemes or categories. There is potential overlap between some categories, either because of conceptual similarities or because of lack of supporting context or reported examples regarding the defined strategies. These are discussed below, as well as the rationale for choosing these categories, subthemes, and themes. Key terms used and characteristic responses are also presented in Table 2. 
Table 2. Resilience-Building Strategies Proposed by Young People in Four LMIC (N=274)

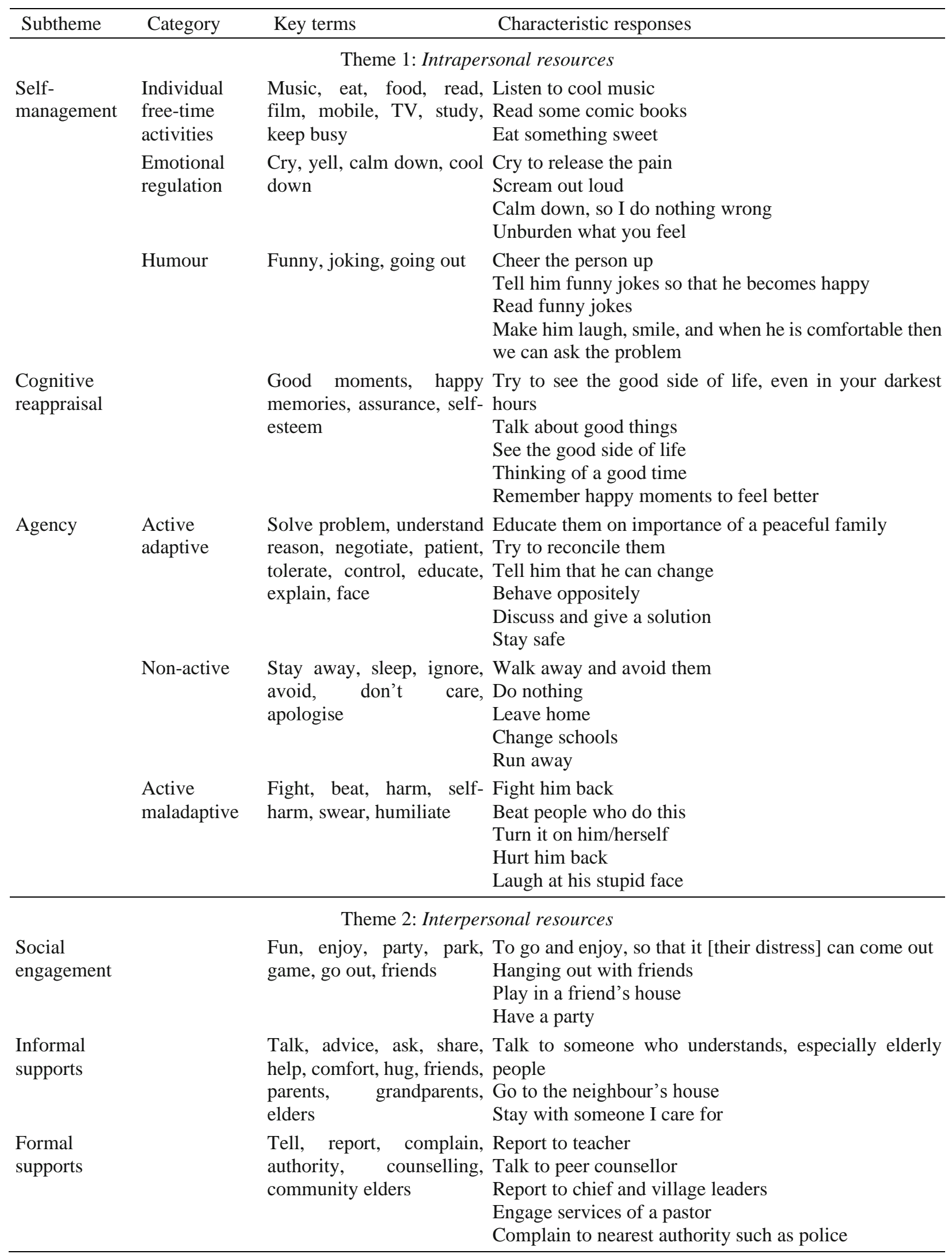


International Journal of Child, Youth and Family Studies (2020) 11(1): 92-111

\begin{tabular}{lll}
\hline Subtheme & Category & Key terms \\
& & Characteristic responses \\
\hline & Theme 3: & Religion \\
& & Pray and forget about it \\
& Encourage him to pray \\
& What goes round comes round \\
& Allah see you and Allah punish you \\
& By the leave of God \\
\hline
\end{tabular}

\section{Theme One: Intrapersonal Resources}

Young people drew on a range of their own resources across sites and scenarios. These included the subthemes of self-management, cognitive reappraisal, and agency, with the young person placing themselves as central to the solution, whether through introspection or through interaction with their environment.

The first subtheme of self-management included the use of individual free-time activities, emotional regulation, and humour. Individual free-time activities appeared to act as generic strategies for space or distraction. These largely consisted of reading, listening to music, and eating. A developmental (teenage) connotation in these strategies appeared to transcend culture (listen to "music", "good music", "cool music", "funk"). Some strategies were framed in the third person, as if recommended to another young person facing the stressor ("focus on his own activity"). Maybe because of their younger age, this category was mostly put forward by participants in Brazil. Interestingly, it was not mentioned at all by young people in care, perhaps because of the care home structure and lack of opportunities to function individually.

Emotional regulation or containment mainly included crying across all groups, followed by screaming ("yell", "scream out loud", "shout"). These seemed to have a cathartic connotation rather than being focused on emotional reprocessing. In contrast, some proposed strategies included a regulatory function ("crying to release the pain", "unburden what you feel"). Several statements indicated relaxation techniques such as "calm down", "take a deep breath", or "count to 10 ". No differences were detected in the use of emotions in dealing with stressors or in distinct emotion-focused strategies at any of the four sites. Children in the care home group did not report any emotion-focused strategies in response to the scenarios. Emotional strategies were evenly reported across the four scenarios.

Humour was the least reported category, but we considered the content of the statements to underpin a distinct concept. Strategies were usually placed in a social context, by "telling jokes" or "making and listening to jokes", or by referring to another young person ("cheer the person up", "we should tell him/her funny jokes, so he/she becomes happy"). A more complex strategy led to tackling the problem: "We will make him laugh, smile, and when he is comfortable, then we can ask the problem." Reframing bullying with humour included "say thank you for giving beautiful name to me" and "I love the name you give me". 
The second subtheme of cognitive reappraisal differed from the first in that there were contextual differences among the first three scenarios. In response to inner feelings of sadness, cognitive strategies included positive appraisal ("see the good side of life", "thinking of a good time"), or forgetting "bad things". An interesting application of cognitive reappraisal of feeling sad was the "happy game" quoted by a Brazilian young person, according to which "in your worst times you try to see the good side of life, even in your darkest hours". When faced with adversity at the level of the home or family, responses included some of the previous strategies of positive appraisal and forgetting, as well as context-related "assurance", potential self-blame ("think whether it is your fault"), distraction ("not concentrate on their arguments"), and recollection of positive family memories ("we can see good memories in the album"). In relation to being bullied at school, the majority of statements reflected internal coping strategies such as minimizing the impact ("we don't mind what he is saying", "will not take seriously"), feeling stronger ("having high self-esteem"), and using moral arguments ("keep the respect of humanity"). Some cognitive responses were directed at the aggressor in "forgiving", "think that person is mad", or "not mind what he is saying".

The third subtheme of agency largely included independent and active responses to the given stressor. Young people thus considered a range of active strategies. These were the most frequently reported in response to the family, school, and community scenarios. Categories were similar across countries, although their content (application) sometimes varied according to the context of the scenario. Strategies common to the scenarios were understanding ("ask reasons") and solving the problem, or a combination of the two (some of which overlapped with interpersonal strategies): “... and when he has more fun, and when we had a lot of fun together, then he can easily share, and will try to solve his problem".

Faced with adversity in the home (parental arguments or fighting), the first steps were neutral listening ("to both sides"), talking ("I kuongekiesha wazazi" ["talking to parents" in Swahili]), and showing love ("hug them"; "Mum, I'm sorry, I love you"; "give a kiss") or offering comfort (snack, ice cream, watch TV). These were followed by active attempts to stop the argument or fight by "reconciling", "educating on importance of peaceful family", or "calming them down". The third step consisted of pointing out the impact of the family conflict on the young person: "it is [having an] effect on my study and behaviours", "try to divert grown-ups attention towards him/her", "I'm gonna run away", and "live on the streets".

The above three processes also emerged in relation to facing adversity at school. Understanding, talking, tolerance ("behaving oppositely"), patience, and attempts at reconciliation ("do an agreement with him to stop bullying") were commonly reported. Education and advice were often interlinked ("... that he can change", "the effects of bullying", "importance of keeping peace and respect", "explaining that I also hurt"). The third and more active - albeit not confrontational, in contrast with a later subtheme - approach emphasized "facing the bully with bravery and intelligence" and being willing to "stand up for your rights": insist on respect, issue a 
warning, but also "smile in front of him". An interesting wider stance was "raising awareness about the effects of bullying".

Strategies responding to the community and neighbourhood scenario were responsive to the local context, but shared conceptual similarities. Solutions to lack of water and electricity showed willingness to actively participate rather than first seeking adult involvement: for water, fetch more from boreholes or rivers, or buy it; for electricity, light candles/lanterns, switch on a generator, or use an emergency light. Community and proactive actions were also suggested such as digging boreholes, planting more trees to attract rain, installing solar energy, and arranging electricity beforehand. Facing crime or a natural disaster predominantly involved safety-first reactions: for crime, staying in the house, locking up doors and windows, and not letting strangers in; for fire, raising the alarm and escaping from the fire. Nevertheless, young people also offered altruistic solutions such as keeping their younger siblings in a room and "acting like a security guard" in the face of violence, raising community awareness against violence (e.g, with a poster), or helping to put a fire out and save other people.

Whether the strategies included in the next subtheme of non-active responses had an adaptive or maladaptive function was often not clear in the absence of elaboration from the young people regarding behaviours such as running away from an incident or leaving a room where parents are arguing. The most common responses denoted distraction and hope for comfort, largely by "doing nothing", sleeping ("hope to see nice and sweet dream", "so cannot be scared"), or keeping busy.

Active but maladaptive strategies came up in every group in response to conflict and aggression. These were verbal, physical, or internalized. When faced with parental conflict, young people considered shouting, involving themselves in the fight, warning parents that they would also fight, being "mischievous", or "slapping both of them". A number of young people from Turkey considered self-harming as a way of acting out their distress. The majority of responses in this category were directed at bullies: arguing, teasing, shouting, swearing, hitting back, punching, hurting, or humiliating the bully ("tell him he is ugly", "laugh at his stupid face"). Certain responses to community violence were particularly aggressive in Brazil ("kill bad guys", "kill [name of local drug lord]"), and Pakistan (by keeping weapons, although one young person stressed that they should be legal).

\section{Theme Two: Interpersonal Resources}

Three subthemes are reported here: social engagement, informal supports, and formal supports.

Social engagement was similar to individual free-time activities in not targeting the stressor, whilst providing the young person with relief and comfort in the presence of others, usually peers. This strategy was predominantly used in response to feeling sad, and occasionally when faced with environmental stressors. Strategies included having "fun"; going on outings 
(friend's house, "hanging out with friends", park, playground); and participating in play or games, creative activities (drawing, dancing), or sports. Some participants defined strategies in relation to helping another young person (usually one who was feeling sad) by giving a gift, telling a story, or organizing a party.

In contrast, seeking informal supports was directly related to the stressor. When feeling sad, friends were almost always the first contact point ("unburden") to talk, share, or "hug"; and occasionally parents also filled this role. When parents argued with each other, grandparents were instead most commonly mentioned, usually for help and advice, although some young people used the words "complain" or "report". The bully's parents were commonly stated as the equivalent contact in the third scenario. In cases of community adversity, parents, community elders, neighbours, friends, and community experts ("rainmakers" in Kenya) would be equally likely to be consulted. Interestingly, young people in care did not specifically mention residential staff as sources of informal support. They mainly connected with their peers ("consider her problem ours"), occasionally their parents, and often non-specific others ("someone" or "adults"), but did not name them as caregivers.

No external formal supports were suggested for the first scenario of feeling sad: these were proposed only in response to external stressors that could not be dealt with through other mechanisms. The boundaries between informal and formal supports were not clear for some sources, namely teachers, elders, and community or spiritual leaders. However, the context of the quotes largely indicated the next step up the help-seeking pathway by using words like "seek", "report", and "complain". A range of school officials and professionals would be sought to address bullying, including a student prefect (a more formal role than peer), class teacher, duty teacher (if urgency were needed), deputy or head teacher, peer counsellor, and teacher with responsibility for guidance and counselling. Teachers were also viewed as a source of help for family conflict, and even as mediators to call the police (which was likely to indicate concerns for domestic violence). Community and religious leaders, and "the nearest authority" — usually the police — were commonly considered as available recourses in response to family conflict. Counsellors, psychologists, and couples therapists were also reported. Responses to community adversity involved the young people themselves seeking help from relevant agencies (fire service, ambulance, police, water or electricity company), or community elders to address the problem ("put the criminals away for the safety of our society"). Young people would directly approach or "complain to" the government, involve the media, and appeal to political leaders (this response came predominantly from the oldest age group in Kenya). Interestingly, young people in care nominated the electricity company as an external source of support, but no other agency.

\section{Theme Three: Religion}

Despite some overlap with cognitive reappraisal, religion was conceptualized as a distinct theme, with similarities across the two major religions of the participating countries (Islam and Christianity in two countries each). Religious strategies were evenly mentioned in response to the 
four scenarios. Praying was the most commonly used. Specific readings (Quran, Bible) or Islamic prayers like Naat, Namaz, and Dua, were considered. Some young people elaborated on the function of praying in relieving fear ("so the fear goes", "to be away from fear"), as a way to "feel better" and help "forget about it", and as a reminder of "stopping you from sins" (in response to parents arguing). In the case of external stressors, religion-related cognitions helped young participants to feel protected (bullying : "Allah see you and Allah punish you"), or to endure the adversity (family conflict: "we think and make ourselves feel good that fights are the deeds of devil, and God is not happy with it"; community violence: "if you're gonna die, you're gonna die"). Young people in Brazil used concepts from a different religion to their own to help them cope with bullying ("wait for Karma", "everything that goes round, comes round"). Young people in Kenya prayed "that God bring rain" and "to God for water".

Overall, no gender differences were detected in the use of resilience-building strategies in response to the four scenarios. However. possible methodological explanations and constraints are considered below.

\section{Discussion}

In this study, we captured the voices of young people from four LMIC on how they defined resilience-building strategies in the face of different scenarios of adversity. The participants gave a range of responses and supporting examples that were themed under intrapersonal, interpersonal, and religious resources. The themes, subthemes, and categories that emerged were broadly consistent across the four cultural groups. Young people sought solutions from different ecological systems, although this also depended on the identified stressor. For example, they would predominantly rely on self-management such as cognitive reappraisal or emotional regulation in response to internalizing problems, but also seek support from family, peers, or elders. Conversely, when faced by external threats and aggression, they would largely access interpersonal resources in addition to seeking external supports, but were less likely to use intrapersonal resources. These findings thus add support to the dynamic linkage between resilience strategies across the ecological systems (Folke, 2016). This theory is not mutually exclusive with viewing resilience strategies as contextualized; that is, as taking place in a particular sociocultural context. Instead, these findings may indicate that broad resilience-building strategies are similar across cultural groups, but are specifically applied depending on the young person's life circumstances. Theron (2018) thus proposed that an ecological systems approach to resilience that is also sensitive to contextual determinants would be a useful model to help young people adapt to apparently intractable risks.

Several concepts could be used in conjunction. For example, young people often linked religious and cognitive responses. It is well established that religion is posited as a specific coping mechanism, with both positive and negative elements, but there are also conceptual differences between religion and cognitive reappraisal; hence we maintained religion as a distinct theme in the analysis (Pargament, 1997; Pargament et al., 2005). The function of certain strategies could be 
viewed according to the underpinning theoretical framework. For example, the type of response that we defined as "maladaptive" (mainly responding with verbal or physical aggression) could be classified under Ungar's (2015) concept of “atypical resilience". Atypical resilience refers to alternative forms of adaptation. While this may appear to be counter-indicative to resilience in certain contexts, it can also be functional in particular contexts of adversity (Ungar, 2011).

Responses across all four sites suggest that, in addition to identifying external resources that they would draw on when faced with adversity, youth did not see themselves as passive recipients of help. Their agency was apparent in the active manner in which they considered each given scenario. For example, young people articulated solutions that involved them as actors instead of merely referring the problem to adults. This was evident across stressors within the family, the school, and the community. They similarly put forward agentic responses to helping their peers and other people when faced with natural or human-induced threats, as well as in regard to enhancing safety and natural resources in their communities.

Emerging differences between contexts need to be acknowledged too. For example, young people in Turkey appeared to adopt more externalizing (fighting back) or internalizing (self-harm) responses to parental arguments and bullying than the other groups. In accordance with this finding, one study conducted in Turkey reported that expressing negative emotions such as swearing and shouting was a common coping strategy among adolescents (Öngen, 2002), although this result was not replicated in a more recent study (Şahin \& Hepsöğütlü, 2018). In contrast, research in Turkey has been consistent in finding that adolescents commonly seek social supports (Altun \& Özdemir, 2018; Kuyumcu et al., 2017; Öngen, 2002).

The group of young people (all female) in care from Pakistan appeared to rely more on interpersonal and peer-related resources, but chose not to turn to their residential caregivers for help and did not know how to access external supports. These vulnerable young people did not consider individual activities, which may have been unavailable because of the structured residential regime. They did not use emotional regulation strategies either, which would be consistent with their multiple traumatic experiences, disrupted attachment relationships, and emotional dysregulation. Worryingly, they did not consider themselves as agents, which could reflect their submissive role within the care system.

Limitations of the research include the relatively heterogenous sampling, and the data collection approach that prevented us from fully understanding either the process through which young people came up with their strategies or the context of their resources. Developing an approach that allows more time and the recording of interactions throughout the small group discussions should be a focus of future research. Sampling variables should also be addressed in more depth. For example, it was not possible to establish the extent of differences between the groups. Age variation was one factor, as the youngest age group from Brazil appeared to suggest more concrete or linear, instead of multilevel, responses; whilst the oldest age group in Kenya considered political protests in response to environmental concerns. However, thr age range of the 
sample was developmentally too wide to address this factor, as it varied from the onset to the end of puberty. These developmental stages can also be culturally-influenced (Sabageh et al., 2015), so future studies should explore children's resilience-building strategies within more targeted age and culture groups.

A similar limitation was the lack of in-depth consideration of gender-related issues, whilst acknowledging that the care home participants were all female Although no gender differences were detected from this dataset, the scenarios were possibly too broad to elicit gender-specific responses. Children's first-line responses could have been followed up by further questioning to understand whether girls and boys used similar or different strategies in response to the same stressor, such as family conflict or school bullying; the participants could also have been asked to formulate gender-specific scenarios (Rizvi et al., 2014). Finally, as both traditional and Western influences were detected in the data, it would also be interesting to explore young people's own explanations of the impact of these influences.

\section{Conclusion}

Several implications for practice and services tentatively arise from these findings. Active participation from young people, indeed from children, is paramount in influencing decisions on their care (United Nations, 2014). Several studies have shown that, when engaged and involved in a developmentally appropriate and sensitive way, even young children can formulate recommendations based on their experiences of psychosocial interventions and services (Bone et al., 2015). In this study, young people responded positively to the participatory research method of participants negotiating their answers in small groups rather than having individual interviews.

The finding that resilience strategies for the same stressor included both informal and formal sources of support indicates the importance of establishing pathways and networks within and across families, communities, and services for young people to receive prompt and comprehensive help. It is recognized that multimodal interventions and scaled service provision are particularly appropriate for young people with complex needs (Hussein et al., 2012; O'Connor et al., 2018; Reed et al., 2011) living in LMIC without access to substantive specialist resources (Vostanis, 2017, 2018; World Health Organization, 2008). Such a service model is consistent with both the ecological systems framework and the multitude of views expressed by young people in this study.

\section{Acknowledgements}

We are grateful to all the young people who took part, and their teachers and parents or caregivers for facilitating contact with them. We thank the organizations that hosted this study as gatekeepers: Friendly Action Network in Kenya; Associação pela Saúde Emocional de Crianças (ASEC) in Brazil; and Hussaini Foundation in Pakistan. 
International Journal of Child, Youth and Family Studies (2020) 11(1): 92-111

\section{References}

Altun, Z. D., \& Özdemir, M. (2018). The role of music in coping with trauma experiences. European Journal of Education Studies, 4, 289-302. doi:10.5281/zenodo.1328275

Bone, C., O’Reilly, M., Karim, K., \& Vostanis, P. (2015). “They're not witches...” Young children and their parents' perceptions and experiences of child and adolescent mental health services. Child: Care, Health and Development, 15, 450-458. doi:10.1111/cch.12161

Braun, V., \& Clarke, V. (2006). Using thematic analysis in psychology. Qualitative Research in Psychology, 3, 77-101. doi:10.1191/1478088706qp063oa

Bronfenbrenner, U. (1979). The Ecology of human development: Experiments by nature and design. Harvard University Press.

Burr, V. (2003). Social constructionism (2nd ed). Routledge.

Folke, C. (2016) Resilience (Republished). Ecology and Society, 21(4), 44. doi:10.5751/ES$\underline{09088-210444}$

Garmezy, N. (1991). Resilience in children's adaptation to negative life events and stressed environments. Pediatric Annals, 20, 459-466. doi:10.3928/0090-4481-19910901-05

Getanda, E., Vostanis, P., \& O'Reilly, M. (2017). Exploring the challenges of meeting child mental health needs through community engagement in Kenya. Child and Adolescent Mental Health, 22, 201-208. doi:10.1111/camh.12233

Huang, C. Y. (2018). Resilience in Taiwan: The shaping forces of its diverse cultural contexts and beliefs about adversity. In G. J. Rich, S. Sirikantraporn, (Eds.), Human strengths and resilience: Developmental, cross-cultural, and international perspectives (pp. 75-86). Lexington.

Hussein, S. A., Vostanis, P., \& Bankart, J. (2012). Social and educational risk factors for child mental health problems in Karachi, Pakistan. International Journal of Mental Health and Culture, 5, 1-14. doi:10.1080/17542863.2010.538187

Johnson, V., Nurick, R., Baker, K., \& Shivakotee, R. (2013). Children and young people's participation (CYPP) training workshop guide. Child Hope.

Kidd, S., \& Kral, M. (2005). Practicing participatory action research. Journal of Counselling Psychology, 52, 187-195. 
Kieling, C., Baker-Henningham, H., Belfer, M., Conti, G., Ertem, I., Omigbodun, O., AgustoRohde, L., Srinath, S., Ulkuer, N., \& Rahman, A. (2011). Child and adolescent mental health worldwide. Lancet, 378, 1515-1525. doi:10.1016/S0140-6736(11)60827-1

King, N. (2004). Using templates in the thematic analysis of text. In C. Cassell, \& G. Symon (Eds.), Essential guide to qualitative methods in organisational research (pp. 256-270). Sage. doi:10.4135/9781446280119.n21

Kuyumcu, B., Yildiz, H., \& Böke, Z. (2017). Lise öğrencilerinin stresle başa çıkma tarzları ve algılanan öğretmen reddinin disiplin durumlarına dayalı olarak incelenmesi [Investigation of high school students coping with stress and perceived teacher rejection based on disciplinary situations]. Yüzüncü Yıl Üniversitesi Eğitim Fakültesi Dergisi [Yüzüncü Y11 University Journal of Education], 14, 1289-1318. doi:10.23891/efdyyu.2017.46

Libório, R. M. C., \& Ungar, M. (2014). Resilience as protagonism: Interpersonal relationships, cultural practices, and personal agency among working adolescents in Brazil. Journal of Youth Studies, 17, 682-696. doi:10.1080/13676261.2013.834313

Maltby, J., Day, L., Zemojtel-Piotrowska, M., Piotrowski, J., Hitokoko, H., Baran, T., Jones, C., Chakravarty-Agbo, A., \& Flowe, H. D. (2016). An ecological systems model of trait resilience: Cross-cultural and clinical relevance. Personality and Individividual Differences doi:10.1016/j.paid.2016.03.100

Masten, A. (2006). Promoting resilience in development: A general system for framework of care. In R. Flynn, P. M. Dudding, \& J. G. Barber (Eds.), Promoting resilience in child welfare (pp. 3-17). University of Ottawa Press.

Masten, A. S., \& Wright, M. O. (2010). Resilience over the lifespan: Developmental perspectives on resistance, recovery and transformation. In J. W. Reich, A. J. Zautra, \& J. S. Hall (Eds.), Handbook of adult resilience (pp. 213-237). Guilford Press.

O’Connor, C., Dyson, J., Cowdell, F., \& Watson, R. (2018). Do universal school-based mental health promotion programmes improve the mental health and emotional well-being of young people? A literature review. Journal of Clinical Nursing, 27, e412-e426. doi:10.1111/jocn.14078

Öngen, D. (2002). Ergenlerde sorunlarla başa çıkma davranışları [Coping behaviors of adolescents]. Eğitim ve Bilim [Education and Science], 27, 54-61.

Organization for Economic Co-operation and Development. (2016). Country risk classification. Retrieved April, 2019 from http://www.oecd.org/tad/xcred/crc.htm 
International Journal of Child, Youth and Family Studies (2020) 11(1): 92-111

Panter-Brick, C. (2015). Culture and resilience: Next steps for theory and practice. In L. C. Theron, L. Liebenberg \& M. Ungar (Eds.), Youth resilience and culture: Commonalities and complexities (pp. 233-244). Springer. doi:10.1007/978-94-017-9415-2_17

Pargament, K. I. (1997). The psychology of religion and coping: Theory, research, practice. Guilford.

Pargament, K. I., Ano, G. G., Falb, M. D., \& Wachholtz, A. (2005). The religious dimension of coping: Advances in theory, research, and practice. In R. F. Paloutzian and C. L. Park (Eds.), Handbook of the psychology of religion and spirituality (pp. 498-609). Guilford.

Patel, V., \& Rahman, A. (2015). Editorial commentary: An agenda for global child mental health. Child and Adolescent Mental Health, 20, 3-4. doi:10.1111/camh.12083

Reason, P. (1994). Human inquiry as discipline and practice. In P. Reason (Ed.), Participation in human inquiry (pp. 40-56). Sage.

Reed, R. V., Fazel, M., Jones, L., Panter-Brick, C., \& Stein, A. (2011). Mental health of displaced and refugee children resettled in low-income and middle-income countries: Risk and protective factors. The Lancet, 379, 250-265. doi:10.1016/S0140-6736(11)60050-0

Rhodes, S. D., Song, E., Nam, S., Choi, S. J., \& Choi, S. (2015). Identifying and intervening on barriers of healthcare access among members of a small community in the southern USA. Patient Education and Counselling, 98, 484-491. doi:10.1016/j.pec.2015.01.001

Rizvi, N., Khan, S. K., \& Shaikh, B. T. (2014). Gender: Shaping personality, lives and health of women in Pakistan. BMC Women's Health, 14(1). doi:10.1186/1472-6874-14-53

Rutter, M. (2006). Implications of resilience concepts for scientific understanding. Annals of the New York Academy of Sciences, 1094, 1-12. doi:10.1196/annals.1376.002

Sabageh, A. O., Sabageh, D., Adeoye, O. A., \& Adeomi, A. A. (2015). Pubertal timing and demographic predictors of adolescents in southwest Nigeria. Journal of Clinical and Diagnostic Research, 9(8), LC11-LC13. doi:10.7860/JCDR/2015/13582.6349

Sahar, N., \& Muzaffar, N. (2017). Role of family systems, positive emotions and resilience in social adjustment among Pakistani adolescents. Journal of Educational, Health and Community Psychology, 6,(2), 46-58. doi:10.12928/jehcp.v6i2.6944

Şahin, S., \& Hepsöğütlü, Z. B. (2018). High school students’ psychological resilience levels and coping strategies. European Journal of Education Studies, 5, 33-44.

doi:10.5281/zenodo.1461008 
International Journal of Child, Youth and Family Studies (2020) 11(1): 92-111

Sirikantraporn, S., Rich, G. R., \& Badaracco, J. C. (2018). The concept of posttraumatic growth in a sample of undergraduates from India: A mixed-methods study. In G.J . Rich, \& S. Sirikantraporn, (Eds.), Human strengths and resilience:Developmental, cross-cultural, and international perspectives (pp. 1-20). Lexington.

Tamburino, I., Getanda, E., O’Reilly, M., \& Vostanis, P. (2018). "Everybody's responsibility": Conceptualisation of youth mental health in Kenya. Journal of Child Health Care. Advance online publication. doi:10.1177/1367493518814918

Theron, L. (2018). Championing the resilience of sub-Saharan adolescents: Pointers for psychologists. South African Journal of Psychology, 49(3), 325-336. doi:10.1177/0081246318801749

Theron, L., \& Phasha, N. (2015). Cultural pathways to resilience: Opportunities and obstacles as recalled by Black South African students. In L. C. Theron, L. Liebenberg, \& M. Ungar (Eds.), Youth resilience and culture: Commonalities and complexities (pp. 51-65). Springer. doi:10.1007/978-94-017-9415-2_4

Theron, L. C., \& Theron, A. (2013). Positive adjustment to poverty: How family communities encourage resilience in traditional African contexts. Culture and Psychology, 19, 391-413. doi:10.1177/1354067X13489318

Theron, L., \& van Rensburg, A. (2018). Resilience over time: Learning from school-attending adolescents living in conditions of structural inequality. Journal of Adolescence, 67, 167178. doi:10.1016/j.adolescence.2018.06.012

Ungar, M. (2004). A constructionist discourse on resilience: Multiple contexts, multiple realities among at-risk children and youth. Youth Society, 35, 341-365. doi: $10.1177 / 0044118 X 03257030$

Ungar, M. (2011). The social ecology of resilience: Addressing contextual and cultural ambiguity of a nascent construct. American Journal of Orthopsychiatry, 81, 1-17. doi:10.1111/j.1939-0025.2010.01067.x

Ungar, M. (2012). Social ecologies and their contribution to resilience. In M. Ungar (Ed.), The social ecology of resilience: A handbook of theory and practice (pp. 13-31). Springer. doi:10.1007/978-1-4614-0586-3_2

Ungar, M. (2015). Resilience and culture: The diversity of protective processes and positive adaptation. In L. C. Theron, L. Liebenberg \& M. Ungar (Eds.), Youth resilience and culture: Commonalities and complexities (pp. 37-50). Springer. doi:10.1007/978-94-017$\underline{9415-2 \_3}$ 
International Journal of Child, Youth and Family Studies (2020) 11(1): 92-111

United Nations. (2014). Mental health matters: Social inclusion of youth with mental health conditions.

https://www.un.org/esa/socdev/documents/youth/IYD2014/reportsocialinclusionofyouthwit hmentalhealth.pdf

United Nations High Commissioner for Refugees. (2013). Operational guidance: Mental health and psychosocial support. https://www.unhcr.org/protection/health/525f94479/operationalguidance-mental-health-psychosocial-support-programming-refugee.html

van Breda, A. D., \& Theron, L. C. (2018). A critical review of South African child and youth resilience studies, 2009-2017. Children and Youth Services Review, 91, 237-247. doi:10.1016/j.childyouth.2018.06.022

Vostanis, P. (2017). Global child mental health: Emerging challenges and opportunities. Child and Adolescent Mental Health, 22, 177-178. doi:10.1111/camh.12246

Vostanis, P. (2018). Hope for children of trauma: An international perspective. Routledge.

Vostanis, P. (2019). World awareness for children in trauma: Capacity-building activities of a psychosocial program. International Journal of Mental Health.

doi:10.1080/00207411.2019.1602019

Vostanis, P., Maltby, J., Duncan, C., \& O’Reilly, M. (2018). Stakeholder perspectives on children's psychosocial needs in six low- and middle-income countries. Children and Society, 32, 457-469.

Vostanis, P., O’Reilly, M., Duncan, C., Maltby, J., \& Anderson, E. (2018). Interprofessional training on resilience-building for children who experience trauma: Stakeholders' views from six low- and middle-income countries. Journal of Interprofessional Care, 33(2), 143152. doi:10.1080/13561820.2018.1538106

Werner, E. E. (1989). High-risk children in young adulthood: A longitudinal study from birth to 32 years. American Journal of Orthopsychiatry, 59, 72-81. doi:10.1111/j.19390025.1989.tb01636.x

Willow, C. (2013) Involved by right: Effective participation of children and young people in alternative care settings. World Awareness for Children in Trauma (WACIT). www.wacit.org [Accessed April, 2019]

World Health Organization. (2008). Mental Health Action Gap Programme: Scaling up care for mental, neurological and substance use disorders. https://www.who.int/mental_health/mhgap_final_english.pdf 